\title{
COMPUTATIONAL METHODS APPLICATION FOR FINDING THE OPTIMAL TRANSPORTATION COSTS
}

\author{
Vukašin Tasićn ${ }^{*}$, \\ Mladen Veinović2 \\ Irena Tasić3 \\ 1PhD Student, \\ Singidunum University, \\ Belgrade, Serbia \\ ${ }^{2}$ Singidunum University, \\ Belgrade, Serbia \\ ${ }^{3}$ The College of academic \\ Studies "Dositej", \\ Belgrade, Serbia
}

\begin{abstract}
:
Computational methods are, among other things, widely used in operational research. Operational research is a complex interdisciplinary field that deals with the problems of decision-making in real conditions, considering all the factors that affect the problem directly or indirectly, in order to find the best, i.e. optimal solution. As there is a growing need for continuous process improvement, there is a growing presence of operational research methods for various real-life problems. The transportation problem is one of the segments of research within operational research. It aims to determine the optimal program of distribution of a certain type of commodity from sources (points of origin) to destinations. The sources are the places where the commodity leaves (the warehouse), while the destinations are the ending points to which the commodity should be transported (in our case - the store). As a criterion for optimizing the transportation of goods, the request for minimizing the total transportation costs is most often taken. In the case of transportation problem, the objective function expresses the total transportation costs, while the limiting conditions are determined by the supply of individual sources (warehouses), i.e. the demand of individual destinations (stores).

This paper discusses the possibility of applying operational research methods in the service sector. The aim of the research part of the paper is to find the optimal solution for real data of a given problem, simulating different conditions and constraints. An experimental analysis was performed for the problem of warehouse operations, and the goal was to minimize the costs of transporting goods. Two different methods were applied in order to determine the optimal solution. Based on the obtained results and their analysis, conclusions were made as to whether the problem was solved.
\end{abstract}

Keywords:

operational research, methods, optimal solution, service sector.
Correspondence:

Vukašin Tasić

e-mail:

tasicvuki@gmail.com

\section{INTRODUCTION}

Among the mathematical methods which optimize control processes, the most developed is the method of linear programming (LP). This method determines the maximum / minimum of the linear objective function, which depends on several variables, provided that these variables are non-negative and that they satisfy linear constraints in the form of equations or inequalities [1]. 
A special case of the general linear programming task is the transportation problem. The formulation of the transportation task is given as follows:

There are $\mathrm{m}$ warehouses that offer certain goods in quantities $a_{1}, a_{2}, \ldots, a_{m}$ and $n$ stores that demand these goods in quantities $b_{1}, b_{2}, \ldots, b_{n}$. The assumption is that the sum of the warehouses' offers is equal to the sum of stores' demand:

$$
a_{1}+a_{2}+\ldots+a_{m}=b_{1}+b_{2}+\ldots+b_{n}
$$

The numbers $c_{i j}$ are given, which indicate the prices of transporting a unit of goods from the $\mathrm{i}$-th warehouse to the $\mathrm{j}$-th store.

Such numbers are to be found $x_{i j} \geq 0$ where $x_{i j}$ indicates the quantity of goods to be transported from the $i$-th warehouse to the $j$-th store so that the total transportation costs are minimal [2].

\section{MATHEMATICAL DEFINITION OF THE TRANSPORTATION PROBLEM}

The optimal transportation plan means the plan of transportation of goods from the warehouse to a certain store, which minimizes the total price of transportation. There are several phases in finding a solution to this problem.

\subsection{PROBLEM FORMULATION}

The transportation problem has a very wide application. The possibility of minimizing the total transportation costs is what is most often sought when it comes to the transportation problem. The starting point is the assumption that the amount of resources to be transported is specified and homogeneous.

The transportation problem requires finding the most rational way of supplying multiple destinations (stores) from several sources (warehouses), while the transportation costs should be minimal [3].

The transportation problem determines the optimal plan for the transportation of one type of goods if the following is known:

1. The number of warehouses (dispatch centres or production centres), from which the transportation of goods should be organized;

2. The number of stores (receiving stations or consumer centres) to which the goods are to be delivered;
3. The quantity of goods in warehouses;

4. The quantity of goods demanded by each store; and

5. The price of transport per unit of goods from each warehouse to each store.

Solving this problem can be divided into three phases:

1. Determining Initial Basic Feasible Solution (IBFS);

2. Evaluating optimality of the obtained solution; and

3. Change of plan.

\subsection{MATHEMATICAL MODEL BUILDING}

- Defining a mathematical programming task $=$ mathematical program (linear or nonlinear);

- Defining the objectivel function (objective function is the objective that is to be achieved by the functioning of the system):

$$
z=f_{\max / \min }\left(x_{1}, x_{2}, \ldots, x_{n}\right)
$$

or this function may consist of multiple criterion functions, the so-called multicriteria optimization;

- Constraint conditions = mathematical relations between variables $x$, that depend on technological requirements, available resources, workspace, etc. [4].

\subsection{DETERMINING THE SOLUTION TO THE PROBLEM}

- Determining the optimal solution $=$ determining the values of the variables $x_{1}, x_{2}, \ldots x_{n}$ that satisfy the constraint conditions and for which the objective function has a maximum or a minimum (depending on what is required in the problem formulation). The optimal solution can be reached analytically for simpler problems (application of mathematical operations such as algebra, differential and integral calculus) and by numerical procedures, where iterative procedures from the assumed initial solution lead to the optimal solution;

1. Sensitivity Analysis Solution = the optimal solution for the selected parameter values is determined and then it is determined how it changes with the changes of parameters [5]. 


\section{PROBLEM FORMULATION AND SOLVING}

Among the tasks of linear programming, a special place is occupied by the transportation problem, due to the characteristic formulation of its mathematical model, which allows significant simplifications in the process of finding the optimal solution [6].

Identification and correct definition of the problem is the initial and relatively most complex phase in the process of obtaining a solution. Unambiguous rules and unique algorithms for problem formulation do not always exist. This phase is characterized by the fact that the experience and creation of the problem analyst should be fully expressed.

When solving the transportation problem, the objective should be defined first, i.e. it should be determined which problem the decision maker wants to solve by using the solution of this problem. Formulation of objectives, which are solved by modeling, must be in accordance with the set time and financial constraints. The objectives should neither be too specific in terms of their context, because the justification of investing in the development of the model can be questioned, nor should they be too general, because solving all possible problems in the considered system by using a single model is not fesible.

Bearing all this in mind, especially the problem which is to be solved, the aim of this paper is to formulate a mathematical model of the transportation problem, where the function of the objective is to minimize transportation costs, i.e. to first determine the initial basic solution and then the optimal solution.

The formulation of a mathematical model implies defining the objective function and constraints. The objective function is to determine the minimum transportation costs, and the constraints are defined by the quantities in the warehouses and the needs of the stores [7].

When solving the problem, we will use several methods to determine the optimal solution, and thus determine which of the methods used provides the lowest price of transporting goods, i.e. the method that provides the best optimal solution.

\section{EXPERIMENTAL ANALYSIS}

We will observe the problem on the model of four warehouses marked with $I_{1} I_{2}, I_{3}$ i $I_{4}$ which have quantities of a product of 26, 23, 29 and $12 \mathrm{t}$ respectively. Transportation costs per unit are given in Table 1.

\begin{tabular}{ccccccc}
\hline & $O_{1}$ & $O_{2}$ & $O_{3}$ & $O_{4}$ & $O_{5}$ & $a_{i}$ \\
\hline$I_{1}$ & 5 & 12 & 1 & 4 & 13 & 36 \\
\hline$I_{2}$ & 7 & 8 & 14 & 6 & 5 & 23 \\
\hline$I_{3}$ & 15 & 4 & 2 & 7 & 9 & 29 \\
\hline$I_{4}$ & 6 & 11 & 5 & 16 & 3 & 12 \\
\hline$b_{j}$ & 13 & 24 & 15 & 21 & 27 & 100 \\
\hline
\end{tabular}

Table 1 - Transportation cost per unit

The transportation plan should be determined so that the total cost of transporting $100 t$ of product is minimal.

The defined problem represents a special form of transportation problem which is solved in two phases:

> The first phase - finding the initial basic solution;

> The second phase - finding the optimal solution.

Prior to finding the initial basic solution, it must be determined whether the transportation problem is "balanced" or "unbalanced". A balanced transportation problem arises due to the ideal balance of supply and demand, i.e. if the quantity of product offered (in our case, the quantity in the warehouse) is equal to the quantity of product demanded (quantity of goods in the store). An unbalanced transportation problem is the disproportion in supply and demand.

Determining the type of transportation problem is done by comparing the sum of the total quantity of goods in the warehouse and the sum of the total quantity of goods demanded by the stores. In our case, it was determined that this is a balanced transportation problem, which is proven by:

$$
\sum a_{i}=\sum b_{\mathrm{j}}=100 t
$$

Upon determining the type of transportation problem, we approach the solution thereof [8].

\subsection{METHODS FOR DETERMINING THE INITIAL BASIC SOLUTION}

Several methods have been used to determine the initial basic solution [9].

1. Upper Left Corner or North-West Corner Method (Dantzig's method).

In its calculation, this method does not consider the value of $c_{i j}$ i.e. unit price, so it is considered the simplest but also the most inefficient method for determining the initial allowable solution of the problem. 
In this method, the calculation is started from the North-West corner (top left corner) from requirement $b_{1}$ in the table and it is compared with the available quantities $a_{1}$. There can be three cases:

> If $b_{1}<a_{1}$, then $b_{1}$ value is assigned to $x_{11}$ and proceeds to cell $x_{12}$, i.e. proceeds horizontally.

, If $b_{1}=a_{1}$ then $b_{1}$ value is assigned to $x_{11}$ and proceeds to cell $x_{22}$, i.e. proceeds diagonally.

> If $b_{1}>a_{1}$ then $a_{1}$ value is assigned to $x_{11}$ and proceeds to cell $x_{21}$, i.e. proceeds vertically.

By using this method, we find that the transportation cost is $\mathrm{T}_{\min }=870$ monetary units.

\section{Least Cost Method (least unit price method)}

This method starts from the cost table and the cell with the lowest cost coefficient is sought; once the cell is found, the largest possible quantity of products allowed by the warehouse or the store is distributed into that cell.

By using this method, we find that the transportation cost is $\mathrm{T}_{\min }=429$ monetary units.

3. The method of the largest difference of the smallest coefficients (Vogel's Approximation Method -VAM)

In this method, we start from the unit costs table, and then for each row and column of that table, the difference between the two smallest elements in the column or row is determined. These differences are entered in an additional column or row. The procedure for allocating costs is as follows: the largest difference between these minimum elements is sought, and then the lowest cost coefficient is sought in that column or row, and the maximum possible quantity of goods to be transported is allocated there. The procedure is repeated until the needs of warehouses and stores are met. By using this method, we find that the transportation cost is $\mathrm{T}_{\min }=392$ monetary units.

\subsection{METHODS FOR FINDING OPTIMAL SOLUTION}

The methods listed below were used for finding the solution to our problem [10] [11].

1. STEPPING STONE METHOD (jumping from stone to stone method)

This is a rather simple method which is particularly suitable if the number of warehouses and stores is not large. Basically, this method is iterative. The first step is to find a basic solution, and then iterations get better and better solutions from it. Iterations are repeated until the optimal solution is obtained.

The starting table is the table that was obtained by one of the methods for finding the solution. We do the procedure of finding variations for each unoccupied cell $\delta_{i j}=\sum c_{i j}$.

The optimality condition is that every $\delta_{i j}>0$.

Relative costs are obtained by "jumping from stone to stone", i.e. by alternating addition and subtraction of unit costs, so that the procedure starts from the cell for which the relative cost is calculated, then continues clockwise onto the occupied cells, depending on the path.

By using this method, we find that the transportation cost is $\mathrm{T}_{\text {min }}=392$ monetary units.

\section{Method of Distribution (MODI)}

This method also finds the optimal solution based on the previously obtained basic solution using some of the previously mentioned methods. Relative costs are calculated according to the formula:

$$
X_{i j}=c_{i j}-\left(u_{i}-v_{j}\right)
$$

where:

> $c_{i j}$ - unit costs;

, $u_{i} \mathrm{i} v_{j}$-coefficients for each basic solution of the values obtained from the formula

$$
c_{i j}=u_{i}+v_{j}
$$

over the occupied cell.

When all the related relative costs in the unoccupied cells in the transportation matrix are positive, the basic solution, which is also the optimal, is obtained. This method results in minimal transportation costs $\mathrm{T}_{\min }=392$ monetary units.

\section{CONCLUSION}

In this paper, we have dealt with a transportation problem that can be applied in any activity. Here we observed the model applicable in the service sector through the transportation of goods from the warehouses to the stores. Given that there is a certain physical distance between the warehouses and the stores, certain costs arise during the distribution and transportation 
of goods. These costs can, among other things, significantly affect the final price of the product. If the transportation costs are high, the price of the product itself will be higher. The transportation problem can be very successfully formulated and solved by using the linear programming model, if the basic requirement for optimizing the transportation of goods is to minimize the total transportation costs.

By modifying the method, a solution to practical problems can be reached. One method of problem solving is almost never enough. Methods and mathematical problems combine with each other to create a new method.

Based on the comparative analysis of data obtained using the methods listed in this paper, we conclude that the costs obtained using the North-West Corner method are the highest, and amount to 870 monetary units, while transportation costs obtained using the VAM method (Vogel method) are closest to the optimal solution and amount to 392 monetary units. Unlike the method of determining the initial basic solution, where we obtained different results by applying different methods, by using any of the methods to find the optimal solution we get the same value of the transportation price. Furthermore, one can notice that the transportation costs obtained by the methods for finding the optimal solution coincide with the transportation costs obtained by the VAM method (Vogel method), which actually means that these costs cannot be further reduced, i.e. that the lowest possible transportation price is obtained.

Based on the methodology presented in this paper, it can be concluded that it is rather complex to standardize the methodology of solving a problem by observing the service sector. The activities in this sector are inherently different, hence the successful implementation of one method in one activity will not ensure the successful implementation of that same method in another activity.

\section{REFERENCES}

[1] S. Krčevinac, M. Čangalović, V. Kovačević-Vujčić, M. Martić i M. Vujošević, Operaciona istraživanja 1, Beograd: Fakultet organizacionih nauka, 2018.

[2] L. Kocić, G. Milovanović i S. Marinković, Operaciona istraživanja, Niš: Elektronski fakultet, 2008.

[3] D. Bogdanović i I. Jovanović, Operaciona istraživanja 1, Bor: Tehnički fakultet, Univerzitet u Beogradu, 2019.

[4] Đ. Dugošija i A. Savić, Operaciona istraživanja: linearno i celobrojno programiranje, grafovi i algoritmi, Beograd: Matematički fakultet, 2018.
[5] D. Pamučar, Operaciona istraživanja, Beograd: Medija centar Odbrana, 2018.

[6] S. Vukadinović, Transportni zadatak linearnog programiranja, Beograd: Naučna knjiga, 1989.

[7] D. Letić i V. Jevtić, Operaciona istraživanja: algoritmi i metode, Zrenjanin: Tehnički fakultet "Mihajlo Pupin", 2007.

[8] O. Todorović, Operaciona istraživanja, Niš: Ekonomski fakultet, 2009.

[9] M. Martić, M. Stanojević, D. Makajić-Nikolić, G. Savić, M. Kuzmanović, B. Panić i B. Andrić Gušavac, Operaciona istraživanja 1: Zbirka zadataka sa praktikumom, 2020: Fakultet organizacionig nauka, Beograd.

[10] S. Borović i M. Milićević, Zbirka zadataka iz odabranih oblasti operacionih istraživanja, Beograd: Medija centar Odbrana, 2004.

[11] I. Tasić, D. Živković i S. Tasić, Zbirka zadataka iz odabranih poglavlja operacionih istraživanja, Vranje: IrisTrade d.o.o., 2018. 